\title{
POPULATION STUDY OF CANADA GEESE \\ OF JACKSON HOLE
}

\author{
Samuel I. Zeveloff \\ Department of Zoology and Physiology \\ University of Wyoming \\ Laramie, Wyoming 82071
}

\section{Objectives}

Although the number of Canada geese (Branta canadensis) in the United States has nearly doubled between 1955 and 1974 , Pacific Flyway populations declined 10 percent (Bellrose, 1976). The decline's causes are not obvious and it may be important to determine the relative role of the individual populations in these dynamics. During earlier work, Dimmick (1968) concluded that the 1964 breeding population of Canada geese in Jackson Hole was stabilized at approximately 300 pairs with 40-47 percent consisting of breeding pairs. In order to determine how dramatic land use changes in this area may have affected the geese, this study compares current conditions and the resulting population status with those of the late 1940's (Craighead and Craighead, 1949) and the early 1960's. Specific objectives of the study are:

1) To conduct a physical inventory of Snake River drainages in Jackson Hole to determine seasonal distribution, size, and productivity of the Canada geese;

2) Identify and evaluate factors influencing goose habitat and productivity; and

3) Formulate management plans for habitat protection and maintenance of optimal goose productivity.

Methods

Intensive surveys of the Snake River drainage in Wyoming are being conducted seasonally to determine numbers and distribution of geese. Aerial censuses are being conducted with the Wyoming Game and Fish Department. Searches for nests near observed singles or pairs commenced in early March, 1979, to establish numbers of geese engaged in breeding compared to those only exhibiting displays. Qualitative and quantitative measurements of abiotic and biotic parameters were made to determine preferred nesting conditions. Eggs have been collected and analyzed by florisil column chromatography for chlorinated hydrocarbons and atomic absorbtion spectroscopy for lead by the Wyoming Department of Agriculture. 
Effects of major land use changes on historical Canada goose habitat will be determined, especially through the use of comparative aerial and satellite photography. Influences exerted by the increase in human populations and the corresponding upsurge in recreational activities in the waterways will be assessed.

\section{$\underline{\text { Results }}$}

Winter activity of Canada geese in Jackson Hole was minimal in early 1979. Various persons reported that small groups of geese were wintering on Blacktail Ponds, on the oxbow in the upper Snake River near Moran, and in the Huckleberry Hot Springs. In late January, I searched for geese in all areas except the last and none were found.

The first evidence of pairing of Canada geese was on March 14 along the Spring Creek drainage of the Snake River. Within a day, additional pairs were observed in other locations south of Jackson and on the National Elk Refuge. Aerial surveys revealed that a total of 405 Canada geese had moved into Jackson Hole by April 29; this population included pairs, females on nests, single males, and groups. The breeding group was composed of 84 pairs and one female on a nest; 38 pairs were observed on a more intensively studied section south of Moose.

Although an early nest building attempt in the snow was noted on March 29, actual nesting first occurred on about April 12 on the National Elk Refuge (J. Wilbrecht, personal communication). Between April 19 and May 7, 17 Canada goose nests were located south of Moose indicating that 45 percent of the pairs were engaged in breeding. An additional 5 nests were found atop haystacks on ranches in the Buffalo River valley.

Hatching was first recorded in early May since goslings were first observed on May 7 near Cabin Creek, the southernmost part of the study area. Thirteen more pairs, 8 with goslings, were spotted during the first two weeks in June along the Snake River between Moran Junction and Moose. Other gosling counts were only obtained for the two broods near Cabin Creek. If these broods are included with the counts of eggs at each nest, the mean clutch size of Canada geese in Jackson Hole in 1979 was 5.05. Other characteristics of the eggs and nests are summarized in Table 1 .

Areas supporting large numbers of molting, feeding, and/or resting Canada geese have recently been described (Zeveloff, 1978). One of these, the Southeast Arm of Yellowstone Lake was revisited in late June, 1979 and approximately 700 geese were observed; a slightly higher concentration than the 400-600 noted a year earlier. With cooperation from Yellowstone National Park and the assistance of the Wyoming Game and Fish Department, 560 geese were banded there to obtain a clearer picture of goose movements from Jackson Hole and Yellowstone Lake to wintering. grounds. Dimmick (1968) argued that much of the Jackson Hole population molts in the vicinity of Yellowstone and Turbid Lakes. 


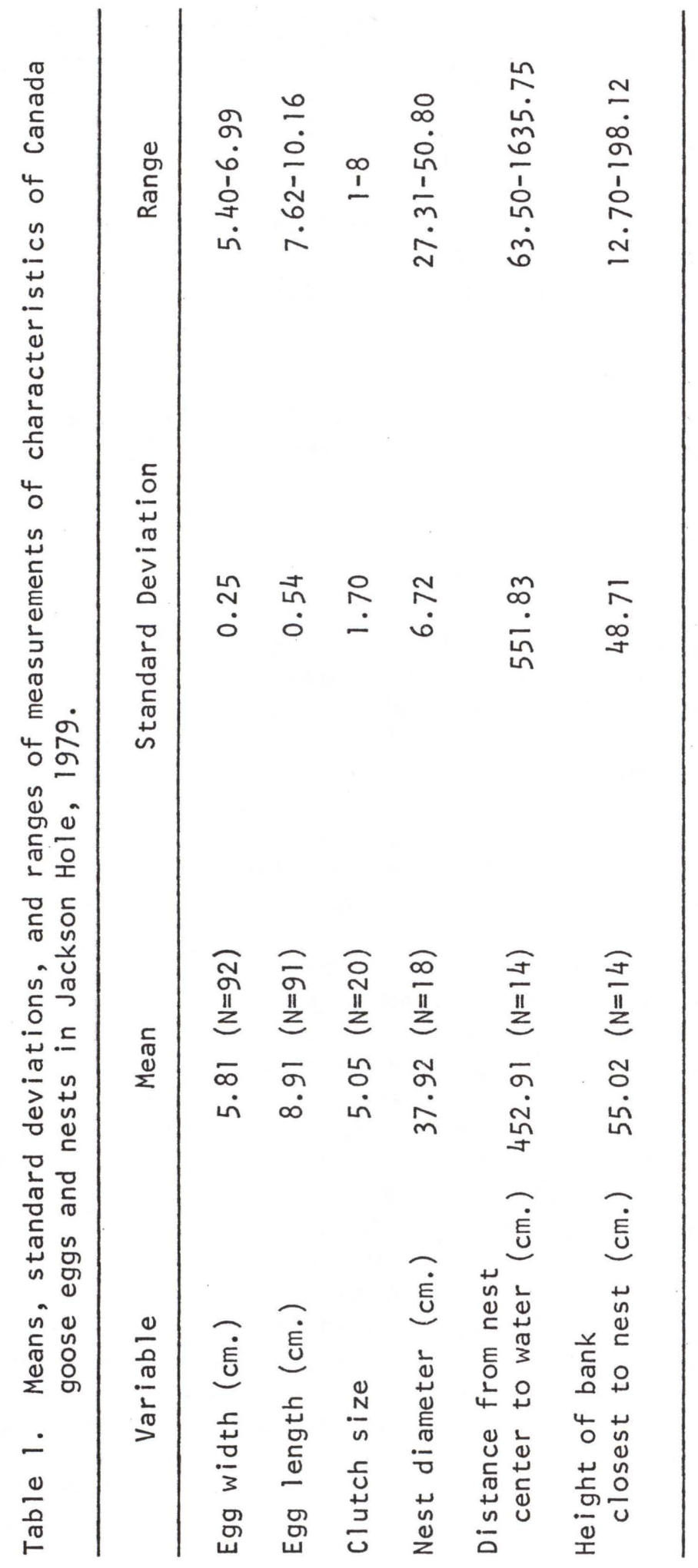


A small sample of Canada goose eggs from northwestern and central Wyoming had a mean total weight of $147.77 \mathrm{~g} . \quad(\mathrm{N}=10)$ and a mean eggshell weight of $17.55 \mathrm{~g}$. $(\mathrm{N}=7)$. Of 7 eggs analyzed, only 1 from Ocean Lake contained the minimum detectable amount of 0.2 parts per million of lead. In 3 eggs from the Bear River near Cokesville, the mean level of toxaphene was 3.04 parts per million $\left(s . d_{.}=0.34\right)$. Unfortunately, toxaphene tends to mask the presence of similar compounds.

I have determined that it is feasible to map Canada goose habitat in Jackson Hole with remote sensing imagery. The Department of Geology at the University of Wyoming either has the necessary imagery or access to information for the same.

An indexed source of references: "A Bibliography of the Canada goose (Branta canadensis)" is near completion. Thus far, it contains over 800 citations on the various aspects of this species' life history printed since 1850 .

\section{Discussion}

Although access problems and cold weather prevented our finding Canada geese in late January, they have been observed on the Snake River throughout previous winters (Craighead and Craighead, 1949; Dimmick, 1968). It is possible that most of the geese did leave the valley though, since this past winter was extremely severe. For the first time in recent years, a large section of the Snake River had ice completely extended over its width (J. Erickson, personal communication). The geese are separated into two spatially isolated flocks in the winter and only a few would remain for its duration in any event (Dimmick, 1968).

Despite the severity of the winter, I still observed a nest building attempt in mid March; Dimmick (1968) found nest site selection did not begin until late March. This early attempt appeared to be headed towards failure because of its placement in snow and the presence of crows (Corvus brachyrhynchos) inspecting a nearby moose (Alces alces) carcass. Normally, nest initiation coincides with the disappearance of snow from nesting areas (Dimmick, 1968) and this was evident in late April and early May. Nesting commenced towards the end of April, about 1 week later than the latest nest initiation period that Dimmick observed and a few days after the laying peak found by the Craighead's (1949). The period during which I first noticed goslings and the mean clutch size are both similar to those found in the other studies in Jackson Hole. The total number of nests (17) located in the area below Moose is considerably less than the total found by Dimmick (1968; p. 32), especially along the Snake River south of Hoback Junction. Perhaps this discrepancy is related to inexperience in nest searching but it is entirely possible that recently constructed flood protection dikes along the rivers have changed hydrology so that much suitable nesting habitat has been eliminated. 
Seventy-three percent of the nests were located on islands; in the other reports referred to, the large majority of nesting also took place on islands. However, the nesting occurs on a variety of island types which is an important safeguard against the loss on an entire nesting effort. The mean distance of the nest to permanent water, $452.91 \mathrm{~cm}$. (Table 1), is less than half the distance reported by the other Jackson Hole Canada goose researchers. Mean bank height was also much lower than the figures of nest height above water of the Craighead's (1949) and Dimmick (1968). This is probably related to the fact that a larger proportion of nests in 1979 were on pond islands than in previous years. The pond islands that I examined were always considerably smaller than those on the rivers. Because nesting was later than usual this year, water release from the Jackson Lake Dam, peaking on June 16 ( $F$. Goodsell, personal communication), may have been particularly catastrophic for late nests and young goslings.

On the Southeast Arm of Yellowstone Lake, I counted more than twice the number of Canada geese than did Dimmick (1968). This may indicate an increase in the total goose population in northwestern Wyoming but the number observed during the aerial breeding survey is comparable to those observed in Jackson Hole 15 years ago (Dimmick, 1968). Perhaps a shift in selection of molting areas has occurred.

The effects of toxaphene on Canada geese has not been adequately researched but the deleterious symptoms it causes have been noted in a few birds (Tucker and Crabtree, 1970). Although it is debatable whether the amount detected is harmful, the spillage of toxaphene from livestock dipping tanks in Wyoming and other states could be problematic.

\section{Summary}

The 1979 breeding survey of Canada geese in Jackson Hole demonstrates that considerably less nesting occurs along the Snake River between the Hoback River and Cabin Creek; Dimmick (1968) counted from 13-16 nests here but 1 only observed 7 . This is an important reduction because of the former high productivity of this area. It may be argued that the alteration of the river's hydrology has affected breeding but subsequent reproductive effort and habitat evaluations are critical. The numbers of breeding pairs between Moran Junction and Wilson, along the Snake River are similar to those found by Dimmick although the southern third of this stretch should have also been affected by the levees. The more recent data is not comparable to that of the Craighead's (1949) since the distribution of actual nests is not discussed.

\section{Acknowledgments}

I would like to thank Dr. Kenneth Diem, Director of the University of Wyoming - National Park Service Research Center for his advice and assistance. The personnel of the Wyoming Game and Fish Department, 
especially J. Erickson, R. Hudelson, J. Kiefling, L. Serdiuk, and G. Wrakestraw, provided assistance at many levels. J. Wilbrecht and K. Ryan of the National Elk Refuge were important in our success in locating nests in that area. Many people associated with Grand Teton National Park, Yellowstone National Park, and Bridger-Teton National Forest were helpful during various phases of the research. K. Alt of Montana State University, R. Guenzel, M. McAdams, and R. Swanson of the University of Wyoming aided in breeding surveys. K. McMillan, chemist at the Wyoming Department of Agriculture laboratory, explained the significance of the toxicant analysis. The generous assistance of all of the above is much appreciated. This study is being supported by a grant from the University of Wyoming - National Park Service Research Center.

\section{$\underline{\text { Literature cited }}$}

Bellrose, F. C. 1976. Ducks, geese, and swans of North America. Stackpole Books, Harrisburg, PA $544 p$.

Craighead, F. C., Jr., and J. J. Craighead. 1949. Nesting Canada geese on the upper Snake River. J. Wild1. Manage. 13:51-64.

Dimmick, R. W. 1968. Canada geese of Jackson Hole, their ecology and management. Wyo. Game and Fish Comm. Bull. No. 11. 86p.

Tucker, R. K., and D. G. Crabtree. 1970. Handbook of toxicity of pesticides to wildlife. Bur. Sport Fish. and Wildl. Resource Publ. No. 84., Washington, D.C. 131p.

Zeveloff, S. I. 1978. Population study of Canada geese of Jackson Hole. Univ. Wyo. - Natl. Park Serv. Res. Ctr. Ann. Rept. $2: 57-61$. 